\title{
Erratum to: Maximal oxygen consumption in healthy humans: theories and facts
}

\author{
Guido Ferretti
}

Published online: 11 January 2015

(C) Springer-Verlag Berlin Heidelberg 2015

Erratum to: Eur J Appl Physiol (2014) 114:2007-2036

DOI 10.1007/s00421-014-2911-0

The author would like to correct the sentence after Eq. (33) in the publication of his review article. It should read as:

The exponent of Eq. (30) is equal to the natural logarithm of $F_{\mathrm{p}}$, an equivalence allowing inclusion of the diffusionperfusion interaction equation for peripheral capillaries in di Prampero's model, and representing a further step towards a more complete representation of the quantitative relations describing oxygen flow at maximal exercise.

The online version of the original article can be found under doi:10.1007/s00421-014-2911-0.

G. Ferretti $(\bowtie)$

Département des Neurosciences Fondamentales, Université de Genève, 1 Rue Michel Servet, 1211 Geneva 4, Switzerland

e-mail: guido.ferretti@unige.ch

G. Ferretti

Dipartimento di Scienze Cliniche e Sperimentali, Università di Brescia, Viale Europa 11, 25123 Brescia, Italy 